\title{
Barriers to adherence with tuberculosis contact investigation in six provinces of Vietnam: a nested case-control study
}

Gregory James Fox ${ }^{1,2^{*}}$, Le Phuong Loan ${ }^{1}$, Nguyen Viet Nhung ${ }^{3}$, Nguyen Thi Loi ${ }^{1}$, Dinh Ngoc Sy ${ }^{3}$, Warwick John Britton ${ }^{2,4}$ and Guy Barrington Marks ${ }^{1,5}$

\begin{abstract}
Background: Close contacts of patients with tuberculosis (TB) have a substantial risk of developing the disease, particularly during the first year after exposure. Household contact investigation has recently been recommended as a strategy to enhance case detection in high-burden countries. However the barriers to its implementation in these settings remain poorly understood.

Methods: A nested case-control study was conducted in Vietnam within the context of a large cluster randomised controlled trial of active screening for TB in household contacts of patients with pulmonary TB. The study population comprised contacts (and their index patients) from 12 Districts in six provinces throughout the country. Cases were contacts (and their index patients) that did not attend the scheduled screening appointment. Controls were those who did attend. We assessed relevant knowledge, attitudes and practices in cases and controls.

Results: The acceptability of contact investigation was high among both cases $(n=109)$ and controls $(n=194)$. Both cases (47\%) and controls (36\%) commonly reported discrimination against people with TB. Cases were less likely than controls to understand that sharing sleeping quarters with a TB patient increased their risk of disease (OR 0.46, 0.27 - 0.78) or recognise TB as an infectious disease (OR 0.65, 0.39 - 1.08). A higher proportion of cases than controls held the mistaken traditional belief that a non-infectious form of TB caused the disease (OR 1.69, 1.02 - 2.78).

Conclusions: The knowledge, attitudes and practices of contacts and TB patients influence their ongoing participation in contact investigation. TB case detection policies in high-prevalence settings can be strengthened by systematically evaluating and addressing locally important barriers to attendance.
\end{abstract}

Trial registration: Australian New Zealand Clinical Trials Registry, ACTRN12610000600044.

Keywords: Tuberculosis, Contact tracing, Screening, Infectious Disease Contact Tracing, Public health, Tuberculosis, Pulmonary, Mycobacterium tuberculosis

\section{Background}

Tuberculosis (TB) control remains a major global public health challenge, with most of the 9 million people affected each year living in resource-limited countries [1]. Despite the widespread availability of effective therapies for TB, the global average decline in incidence has been only $2 \%$ annually. It is estimated that, each year, three

\footnotetext{
* Correspondence: gregory.fox@sydney.edu.au

'Woolcock Institute of Medical Research, University of Sydney, 431 Glebe Point Road, Glebe, Sydney 2037, Australia

${ }^{2}$ Sydney Medical School, University of Sydney, Sydney 2006, Australia

Full list of author information is available at the end of the article
}

million new cases of TB remain undiagnosed [1]. Actively screening high-risk groups for TB could increase the proportion of infectious cases that are diagnosed and treated and, thereby, reduce ongoing transmission of $\mathrm{TB}$ in the community [2,3]. Household contacts of patients with TB have a higher risk of developing TB than the general population. A recent meta-analysis of published contact investigation studies showed that, overall, 3.1\% (95\% CI 2.2-4.4\%) of household contacts had TB disease at the time their infectious household member was diagnosed [4]. The study also showed high rates of incident TB over the four years following enrolment, suggesting that serial screening of

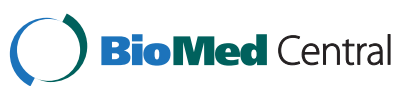

(c) 2015 Fox et al.; licensee BioMed Central. This is an Open Access article distributed under the terms of the Creative Commons Attribution License (http://creativecommons.org/licenses/by/4.0), which permits unrestricted use, distribution, and reproduction in any medium, provided the original work is properly credited. The Creative Commons Public Domain Dedication waiver (http://creativecommons.org/publicdomain/zero/1.0/) applies to the data made available in this article unless otherwise stated. 
contacts is a high yield strategy. Evidence from communitybased studies also points towards a possible impact upon the burden of TB in high-prevalence settings [5].

Over the past decade, WHO recommended screening for TB in high-risk groups including household contacts [6], child contacts under 5 years [7] and contacts who are HIV infected [8]. National Tuberculosis Programs in high-prevalence settings have sought to apply these policies in their local contexts [9]. However, they have faced substantial challenges in bridging the gap between screening policies and practice [10]. In particular, convincing asymptomatic contacts to attend screening appointments has been difficult. Understanding the barriers to screening from the perspective of patients and their contacts is critical to the development of effective contact investigation strategies [11-13].

This study aimed to characterise knowledge about TB and perceived barriers to participation in contact investigation among household contacts of adult patients with pulmonary TB managed within the Vietnam National Tuberculosis Program.

\section{Methods}

\section{Setting}

Vietnam is a south-east Asian country with a persistently high prevalence tuberculosis (209 prevalent cases of TB per 100000 population), despite having achieved good treatment outcomes for over a decade [1]. Consequently, enhanced case finding strategies, such as contact investigation, are a priority for Vietnam. The National TB Program has recently adopted a policy of routine symptom screening and preventive therapy for child contacts. However screening of adult contacts is not performed routinely [14].

\section{Study design}

We conducted a nested case-control study between September 2010 and July 2012 at District TB clinics participating in a larger randomised controlled trial (RCT) of contact investigation that is being undertaken in 8 Provinces throughout Vietnam [15]. District TB units are the primary location of TB diagnosis and treatment for the National TB Program, with chest radiography available at most sites. In the main RCT, which is described elsewhere [15], 70 District TB units were randomised to be either the intervention or control group. Over 10,000 contacts of patients with smear positive pulmonary $\mathrm{TB}$ were recruited in each group. In the intervention Districts, 'index' TB patients were asked to bring all household contacts to their local District TB unit for screening four times in two years: at the time of the patient's initial diagnosis, then after six, 12 and 24 months.

District TB units that were randomised to the intervention group were eligible for inclusion in the case-control study if they had demonstrated their capacity to recruit contacts during the early phase of the RCT. This was defined as recruiting at least $50 \%$ of eligible index patients, based upon case notification data. This approach was chosen to ensure that health system-related factors alone did not drive the non-attendance of contacts. Based on this criterion, 12 of 36 intervention Districts from the six of the eight provinces in the main study were selected. The study population for the present case-control study comprised all contacts within these 12 Districts that had been enrolled in the main study before $30^{\text {th }}$ September 2011. Within this study population, cases were those who did not attend their scheduled six-month follow-up visit (that is, the first scheduled review after enrolment into the main study) and controls were selected at random from among those who did attend this appointment.

\section{Questionnaire development and data collection}

Contacts were interviewed by District TB clinic staff, using a structured questionnaire (Additional file 1), to ask about their knowledge and attitudes relating to contact investigation. The 'index' patients of enrolled contacts also completed a questionnaire. All questionnaires were manually checked for completeness and consistency by study staff, and $10 \%$ of contacts were randomly re-interviewed by Provincial staff to verify the accuracy of responses.

Knowledge, attitudes and beliefs about TB were measured using a questionnaire that was administered to all selected cases and controls (and their index patients).

The questionnaire was developed based upon a review of the literature, and three focus group discussions including 26 household contacts and their index patients and health care workers involved in a pilot contact investigation study [16]. Discussion themes were identified by a search of relevant literature and consultation with local physicians. Recordings from the discussions were transcribed, coded and analyzed according to the grounded theory method [17]. The final questionnaire was based on themes arising from the discussions, as well as themes identified in published literature relating to knowledge about $\mathrm{TB}$, attitudes towards contact investigation, and compliance with $\mathrm{TB}$ screening.

\section{Data analysis}

Qualitative interviews were recorded digitally, transcribed and translated into English before coding and analysis.

Questionnaire responses were independently entered twice using EpiData 3.1 [18]. Groups of contacts were compared using generalized estimating equations (GEE), with clustering at the level of the index patient. Effects were estimated as odds ratios and 95\% confidence intervals. Model covariate selection in multivariate analysis was based upon quasi-likelihood under the independence model criteria (QIC) using reverse covariate selection. Data were analyzed 
using SAS (v9.3, SAS Institute, Cary, NC). Variables with $<10 \%$ of missing values were imputed using multiple imputation [19], and those with a higher proportion of missing values were excluded.

We estimated that 136 cases and an equal number of controls would yield $80 \%$ power to detect a $40 \%$ difference in the prevalence of positive responses between cases and controls as significant (at the $5 \%$ level).

\section{Ethics approval and consent}

This study was approved by the Human Research Ethics Committee of the University of Sydney, and the Institutional Review Board of the National Lung Hospital, Hanoi, and was conducted in accordance with the principles of the Helsinki Declaration. Study participants provided written informed consent. The main RCT within which this study was nested (the ACT2 study) has been registered in the Australian New Zealand Clinical Trials Registry ACTRN12610000600044.

\section{Results}

\section{Participant demographics}

Among 812 eligible contacts participating in the main RCT in the 12 intervention Districts, all 109 'non-attenders' (cases) and 194 selected 'attenders' (controls) agreed to participate in this study (Figure 1). In addition, the 162 index patients of these contacts agreed to complete a questionnaire.

The median age of contact participants was 35 years (interquartile range, IQR, 18 - 50) among cases and 33 years (IQR 20-49) among controls (Table 1) and 60\% and $58 \%$, respectively, were female. More cases than controls had previously been treated for TB, although the $95 \%$ confidence interval crossed the null (OR 1.36, 0.41 -4.47). Cases were less likely than controls to be from the south of the country than the north (OR $0.43,0.21-0.88$ ). The majority of contacts traveled to the clinic by motorbike (84\% among cases and 83\% among controls). The proportion living more than $10 \mathrm{~km}$ from the District TB Unit was similar in cases $(28 \%)$ and controls (27\%).

\section{Contacts' attitudes and knowledge about TB and TB screening}

There was strong acceptance of TB contact investigation in both groups, with $83 \%$ of cases and $88 \%$ of controls believing the program to be beneficial (Table 2). Both groups appreciated the increased risk of TB among contacts (70\% and $69 \%$ respectively), and recognized that TB can severely affect their health (83\% and $89 \%$ respectively). A perception of discrimination against TB in the community was more common among cases than controls (47\% versus $36 \%$, OR $1.55,0.95-2.51$, adjusted for region and prior TB). Cases were less likely to understand that TB was caused by an infectious organism (adjusted OR 0.65, 0.39 - 1.08), and were

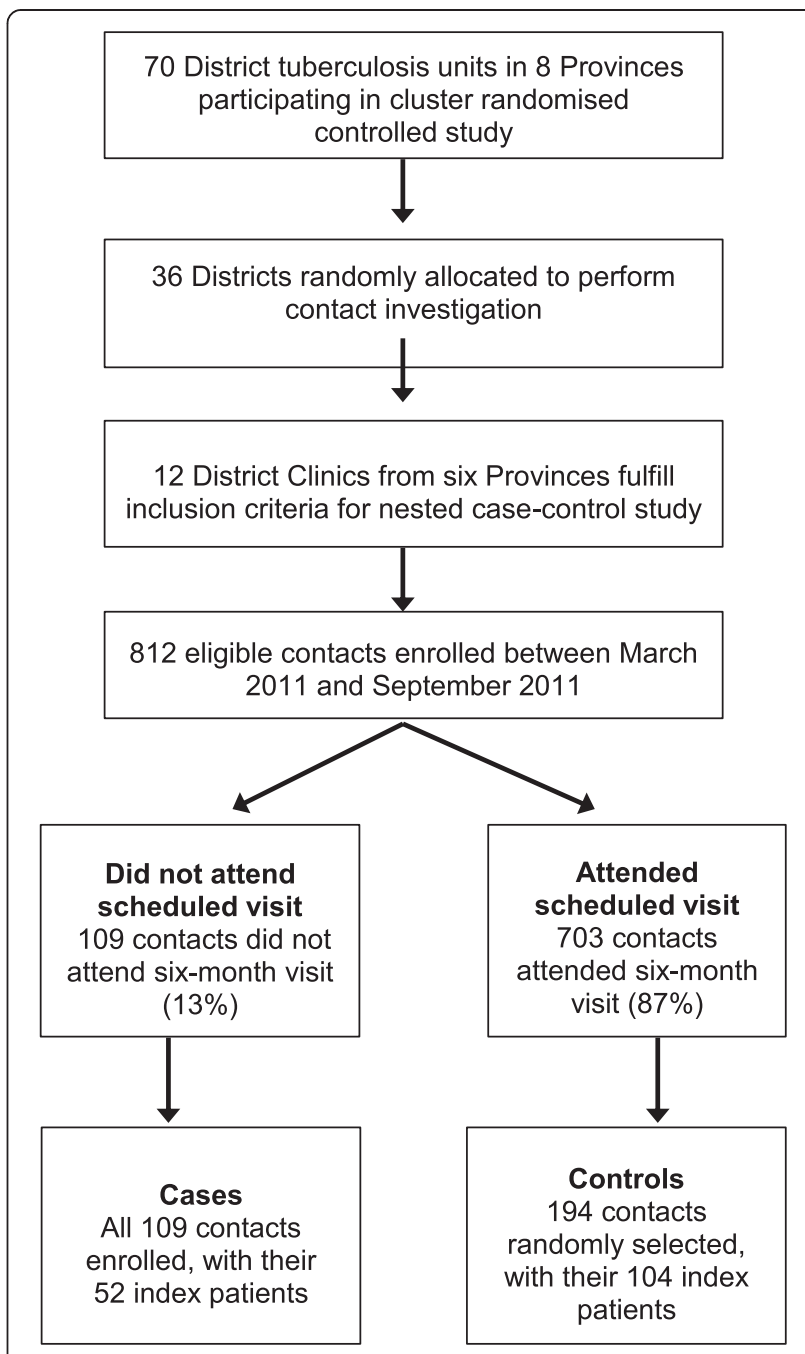

Figure 1 Consort diagram of study recruitment.

less likely to perceive that sharing a bedroom increased the risk of transmission (adjusted OR 0.46, 0.27 - 0.78). A higher proportion of cases also held a mistaken traditional belief that a non-infectious 'exhaustible' form of TB [20] could cause the disease (adjusted OR 1.69, 1.02 - 2.78). Overall, $98 \%$ of cases and $97 \%$ of controls correctly believed that smoking tobacco was associated with an increased risk of developing TB, however a high proportion incorrectly attributed infection to sharing of utensils (cases 74\%, controls $80 \%$ ) or clothing or towels (61\% and 55\% respectively). Only $11 \%$ and $6 \%$ of cases and controls, respectively, believed that Vietnamese traditional medicines alone could cure TB, while most viewed Western medicines as curative (93\% in both groups).

\section{Factors affecting attendance at follow-up}

When asked about barriers to attending screening $41 \%$ of cases identified the distance between the clinic and their house as a barrier to participation (Table 3). $43 \%$ of cases 
Table 1 Demographic characteristics of participating household contacts

\begin{tabular}{|c|c|c|c|c|c|}
\hline Characteristics & & \multicolumn{2}{|l|}{ Cases $^{+}$} & \multicolumn{2}{|l|}{ Controls ${ }^{*}$} \\
\hline Total & & 109 & & 194 & \\
\hline Gender & Female & 65 & $(60 \%)$ & 113 & $(58 \%)$ \\
\hline \multirow[t]{2}{*}{ Median age, years (IQR) } & 35 & & & & \\
\hline & & $(18-50)$ & 33 & $(20-49)$ & \\
\hline \multirow[t]{3}{*}{ Region of Vietnam } & North & 19 & $(17 \%)$ & 16 & $(8 \%)$ \\
\hline & Centre & 20 & $(18 \%)$ & 40 & $(21 \%)$ \\
\hline & South & 70 & $(64 \%)$ & 138 & $(71 \%)$ \\
\hline \multirow[t]{2}{*}{ Setting } & Rural & 52 & $(48 \%)$ & 81 & $(42 \%)$ \\
\hline & Urban & 57 & $(52 \%)$ & 113 & $(58 \%)$ \\
\hline Prior TB history & & 10 & $(9 \%)$ & 10 & $(5 \%)$ \\
\hline \multirow[t]{5}{*}{ Relationship to TB patient } & Parent & 17 & $(16 \%)$ & 35 & $(18 \%)$ \\
\hline & Spouse & 31 & $(28 \%)$ & 59 & $(30 \%)$ \\
\hline & Child & 39 & $(36 \%)$ & 64 & $(33 \%)$ \\
\hline & Sibling & 7 & $(6 \%)$ & 18 & (9\%) \\
\hline & Other relative & 15 & $(14 \%)$ & 18 & (9\%) \\
\hline \multirow[t]{6}{*}{ Highest education level ${ }^{\#}$} & No schooling & 4 & $(4 \%)$ & 16 & $(8 \%)$ \\
\hline & Primary (grades 1-5) & 26 & $(25 \%)$ & 50 & $(26 \%)$ \\
\hline & Secondary (grades 6) & 29 & $(28 \%)$ & 55 & $(29 \%)$ \\
\hline & High school (grades 7+) & 32 & $(31 \%)$ & 45 & $(24 \%)$ \\
\hline & Tertiary & 10 & $(10 \%)$ & 17 & $(9 \%)$ \\
\hline & Vocational training & 3 & $(3 \%)$ & 7 & $(4 \%)$ \\
\hline \multirow[t]{6}{*}{ Current occupation" } & Full time employee & 14 & $(16 \%)$ & 31 & $(20 \%)$ \\
\hline & Unemployed & 7 & $(8 \%)$ & 10 & $(6 \%)$ \\
\hline & Student & 20 & $(22 \%)$ & 41 & $(26 \%)$ \\
\hline & Part time employee & 0 & $(0 \%)$ & 2 & $(1 \%)$ \\
\hline & Retired & 9 & $(10 \%)$ & 9 & $(6 \%)$ \\
\hline & Self-employed & 39 & $(44 \%)$ & 63 & $(40 \%)$ \\
\hline \multirow[t]{3}{*}{ Monthly income ${ }^{* *}$} & $<\$ 25 /$ month & 21 & $(26 \%)$ & 32 & $(23 \%)$ \\
\hline & $\$ 25$ to $\$ 250 /$ month & 52 & $(64 \%)$ & 97 & $(71 \%)$ \\
\hline & $>\$ 250 /$ month & 8 & $(10 \%)$ & 8 & $(6 \%)$ \\
\hline
\end{tabular}

*'Cases' were contacts that did not attend their scheduled appointment. ${ }^{+}$Controls' were contacts that attended their scheduled appointment. ${ }^{~ E d u c a t i o n a l ~ l e v e l ~}$ provided by $104 / 109$ cases and 190/194 controls. " $89 / 94$ cases and $156 / 194$ controls stated their occupation. ${ }^{* *} 81 / 109$ cases and $137 / 194$ controls stated their monthly income.

found difficulties taking time off work or study to attend the appointment. Significantly more cases than controls believed that once the index patient was screened then there was no need for screening (adjusted OR 2.30, $1.25-4.24) .70 \%$ of cases reported forgetting their scheduled appointment.

The index patients of cases were more likely than patients of controls to believe that specific risk groups, namely pregnant women (OR 3.43, 1.53 - 7.70) and people with immune impairment (OR 4.8, 1.37 - 16.83) were more likely to develop TB (Additional file 2: Table S1). The perceptions of stigma, and benefits of screening, were similar in index patients of cases and contacts.

\section{Discussion}

This case-control study, nested within a RCT of serial contact investigation in 70 Districts throughout Vietnam, characterised the knowledge and attitudes of participants towards TB and contact investigation. A substantial proportion of contacts and index patients identified discrimination 
Table 2 Perceptions of tuberculosis and tuberculosis screening among contacts

\begin{tabular}{|c|c|c|c|c|c|c|}
\hline \multirow[b]{2}{*}{ Response } & \multicolumn{2}{|c|}{ Non-attendee responses (cases) } & \multicolumn{2}{|c|}{ Attendee responses (controls) } & \multicolumn{2}{|c|}{ Odds of non-attendance } \\
\hline & $\mathrm{n}$ & $(\%)$ & $\mathrm{n}$ & $(\%)$ & $\mathrm{OR}_{\mathrm{adj}}$ & $95 \% \mathrm{Cl}$ \\
\hline Total & 109 & & 194 & & & \\
\hline \multicolumn{7}{|l|}{ Contact attitudes towards TB } \\
\hline $\begin{array}{l}\text { Perceive discrimination against TB } \\
\text { from outside the family }\end{array}$ & 51 & $(47 \%)$ & 70 & $(36 \%)$ & 1.55 & $(0.95-2.51)$ \\
\hline $\begin{array}{l}\text { Believe that own risk of TB as being } \\
\text { higher than the general population }\end{array}$ & 76 & $(70 \%)$ & 134 & $(69 \%)$ & 1.2 & $(0.69-2.07)$ \\
\hline $\begin{array}{l}\text { Believe TB screening is beneficial for } \\
\text { their family }\end{array}$ & 91 & $(83 \%)$ & 171 & $(88 \%)$ & 0.55 & $(0.26-1.15)$ \\
\hline \multicolumn{7}{|l|}{ Knowledge and attitudes about TB } \\
\hline \multicolumn{7}{|l|}{ TB can be transmitted by } \\
\hline Sneezing & 41 & $(38 \%)$ & 62 & $(32 \%)$ & 1.39 & $(0.84-2.29)$ \\
\hline Talking & 79 & $(72 \%)$ & 149 & $(77 \%)$ & 0.77 & $(0.44-1.32)$ \\
\hline Sharing utensils & 81 & $(74 \%)$ & 156 & $(80 \%)$ & 0.66 & $(0.37-1.16)$ \\
\hline Sleeping in the same bedroom & 70 & $(64 \%)$ & 150 & $(77 \%)$ & 0.46 & $(0.27-0.78)$ \\
\hline Sharing towels, clothes etc. & 67 & $(61 \%)$ & 107 & $(55 \%)$ & 1.25 & $(0.77-2.03)$ \\
\hline Hugging or kissing & 71 & $(65 \%)$ & 143 & $(74 \%)$ & 0.61 & $(0.36-1.03)$ \\
\hline Sharing the same toilet & 29 & $(27 \%)$ & 40 & $(21 \%)$ & 1.32 & $(0.75-2.31)$ \\
\hline Having sexual intercourse & 15 & $(14 \%)$ & 20 & $(10 \%)$ & 1.52 & $(0.74-3.13)$ \\
\hline \multicolumn{7}{|l|}{ TB is caused by* } \\
\hline An infectious organism & 56 & $(55 \%)$ & 126 & $(68 \%)$ & 0.65 & $(0.39-1.08)$ \\
\hline Living in an unhygienic environment & 85 & $(83 \%)$ & 139 & $(75 \%)$ & 1.71 & $(0.91-3.21)$ \\
\hline Inheriting the disease from your parents & 33 & $(32 \%)$ & 48 & $(26 \%)$ & 1.44 & $(0.84-2.46)$ \\
\hline $\begin{array}{l}\text { A form of 'exhausted TB' which is not } \\
\text { transmissible }\end{array}$ & 64.0 & $(63 \%)$ & 93 & $(50 \%)$ & 1.69 & $(1.02-2.78)$ \\
\hline \multicolumn{7}{|l|}{$\begin{array}{l}\text { The following people have a higher } \\
\text { risk of developing } T^{*}\end{array}$} \\
\hline Tobacco and bong smokers & 100 & $(98 \%)$ & 180 & $(97 \%)$ & 1.47 & $(0.29-7.45)$ \\
\hline Children & 79 & $(77 \%)$ & 141 & $(76 \%)$ & 0.99 & $(0.55-1.77)$ \\
\hline Pregnant women & 72 & $(71 \%)$ & 138 & $(74 \%)$ & 0.8 & $(0.46-1.38)$ \\
\hline $\begin{array}{l}\text { People with weakened immune systems } \\
\text { such as diabetes }\end{array}$ & 84 & $(82 \%)$ & 154 & $(83 \%)$ & 0.9 & $(0.47-1.71)$ \\
\hline People with poor nutrition & 91 & $(89 \%)$ & 170 & $(91 \%)$ & 0.77 & $(0.34-1.74)$ \\
\hline \multicolumn{7}{|l|}{ Treatment and cure of TB* } \\
\hline $\begin{array}{l}\text { TB can be completely cured if a person } \\
\text { takes treatment }\end{array}$ & 102 & $(100 \%)$ & 183 & $(98 \%)$ & na & \\
\hline Traditional medicine can cure TB & 12 & $(12 \%)$ & 12 & $(6 \%)$ & 2.07 & $(0.89-4.84)$ \\
\hline Western medicine can cure TB & 101 & $(99 \%)$ & 180 & $(97 \%)$ & 4.43 & $(0.51-38.82)$ \\
\hline TB can severely affect your health & 91.0 & $(89 \%)$ & 173 & $(93 \%)$ & 0.83 & $(0.34-2.04)$ \\
\hline
\end{tabular}

$\mathrm{OR}_{\mathrm{adj}}$ - Adjusted odds ratio. $\mathrm{Cl}$ - Confidence interval. $\mathrm{n}$ - number of responses. Adj $=$ adjusted for region and prior TB status. ${ }^{*} 102$ case subjects and 194 control subjects responded.

against people with $\mathrm{TB}$ as an important issue, while most believed that screening contacts for TB was beneficial. Cases were less likely to understand TB as an infectious disease, and misunderstandings about the biology of disease and transmission were common.
For the long-term ambition of global TB elimination to be realized [21], new strategies are needed to substantially enhance case-finding and thereby reduce transmission in the community. Consequently, recent WHO policies have provided a framework for the expansion of TB screening 
Table 3 Explanations by cases for non-attendance at follow-up

\begin{tabular}{|c|c|c|}
\hline & $\mathrm{n}$ & (\%) \\
\hline Total & $105^{+}$ & \\
\hline \multicolumn{3}{|l|}{ Case responses* } \\
\hline The distance from my house to the clinic is too far & 43 & $(41 \%)$ \\
\hline I am worried about harmful effects of X-ray & 28 & $(27 \%)$ \\
\hline I prefer to be examined in a private clinic instead & 20 & $(19 \%)$ \\
\hline $\begin{array}{l}\text { I am worried about discrimination from other } \\
\text { people towards myself and my family }\end{array}$ & 28 & $(27 \%)$ \\
\hline $\begin{array}{l}\text { The patient in my house recovered, so } \\
\text { follow-up screening is not necessary }\end{array}$ & 33 & $(32 \%)$ \\
\hline I initially forgot the scheduled appointment & 73 & $(70 \%)$ \\
\hline $\begin{array}{l}\text { The initial screening was negative, so I did } \\
\text { not see the need for further screening }\end{array}$ & 25 & $(24 \%)$ \\
\hline $\begin{array}{l}\text { It was time consuming, and difficult } \\
\text { to get time off work or study }\end{array}$ & 45 & $(43 \%)$ \\
\hline
\end{tabular}

${ }^{+}$The denominator for individual questions differs slightly for each question, based on the number of valid responses. *Indicates an affirmative response.

in a range of high-risk populations, including household contacts $[6,22]$. However, if enhanced case-finding strategies are to be successful, international recommendations must be adapted successfully to local clinical contexts [23]. Consequently, it is important that before 'scaling up' new screening programs, National TB programs and local health services should consider how local attitudes towards TB screening are likely to influence their success.

This study has identified a number of important misconceptions about the natural history of TB that are likely to affect attendance. One third of cases believed that they were no longer at risk once the TB patient in their household had completed treatment, and one quarter believed an initial negative test was sufficient to exclude subsequent disease. This reflects a lack of understanding about the nature of latent tuberculous infection, which can frequently lead to tuberculosis months or years after the initial exposure [4]. This is likely to reduce motivation to attend serial screening for disease. For contact investigation programs to achieve high rates of re-screening, participants must be educated about their ongoing risk of disease. This finding emphasizes the importance of National TB Programs delivering clear and accurate information to contacts about their ongoing risk of reactivation in the several years after exposure, at the time of initial screening.

Many contacts were also confused about the way in which TB is transmitted. Over one third of contacts who did not attend their appointment did not believe TB was transmissible. Over $70 \%$ of contacts incorrectly believed that sharing utensils or other common property could transmit TB. While these beliefs could heighten their perception of risk and motivate their desire to participate in screening, fear of contagiousness may also lead to discrimination against people with TB and increase their sense of alienation from society. Simple educational interventions to explain the airborne nature of $\mathrm{TB}$ transmission can be incorporated into screening programs to combat this misperception.

Importantly, over half of all contacts hold the traditional Vietnamese belief that an 'exhausted' form of TB is noninfectious, as previously described [20]. In our focus groups some participants described this form of disease as indicating an intrinsic weakness within a family. This idea, although not biologically accurate, is understandable given the observed household clustering and known genetic risk factors for TB. These attitudes and beliefs may further exacerbate a sense of alienation among affected individuals. It is not surprising that this notion was more common among those who did not attend contact screening than among those who did attend.

Importantly, we found that $45 \%$ of Districts required contacts to travel more than $500 \mathrm{~m}$ from the District clinic to access external radiology facilities. This is likely to prolong each screening encounter. Similar difficulties accessing clinical services have also been shown to reduce treatment compliance in patients treated for active TB in other settings [24-26]. As over one quarter of contacts in our study lived over $10 \mathrm{~km}$ from the screening clinic, consideration should to be given to a more decentralised approach to screening, particularly in rural areas. Another common barrier to attendance was difficulty remembering appointment dates and times. Innovative strategies, such as scheduled mobile phone based prompts using SMS, or written follow-up reminders could provide a simple and effective solution to address this difficulty. Hence, both practical and psychosocial barriers to attendance need to be addressed by the health service, as local contact investigation strategies are developed and scaledup in Vietnam.

Observations from this study are highly relevant to other comparable high-burden settings where contact investigation is to be implemented. National TB Programs considering implementing or scaling up contact investigation programs may benefit from conducting similar research to identify locally-relevant barriers to implementation. Surveying participants during the early stages of a newly introduced contact investigation program can provide helpful information for health managers, in order to modify screening processes, improve accessibility, refine health promotion materials and focus National TB Program staff training.

A potential limitation of this study was that contacts selected for the study had already enrolled in the main contact investigation study. For both ethical and practical reasons, it is difficult to evaluate the opinions of subjects who are unwilling to enroll in a study. While selection bias may have 
underestimated the prevalence of perceived barriers to accessing screening among contacts, it is likely to bias effect estimates towards the null. Nonetheless, we identified barriers using both qualitative methods (focus groups) and quantitative approaches in 12 Districts, in 6 provinces, nested within our main study. Consequently, it is likely that these represent important factors common to many potential participants in contact investigation. Hence, our results have been useful in developing resources to improve participation in the main study, and will enhance the expansion of contact investigation in Vietnam.

This study has demonstrated that contacts and patients in Vietnam commonly perceive prejudice against TB, although most participants did not feel this directly affected them. By identifying some important misunderstandings about TB transmission and pathogenesis, we have identified factors that, if addressed, may improve participation and retention in contact investigation programs.

\section{Conclusions}

In conclusion, contact investigation is a promising intervention for improving $\mathrm{TB}$ case detection. It benefits both individuals and the community. By evaluating the experience of contact investigation from a range of perspectives, TB programs can better understand the way in which their policies operate in practice. These insights can improve the way in which health care is delivered in order to improve the experience of screening participants and strengthen TB control.

\section{Additional files}

Additional file 1: Questionnaire for tuberculosis patients and their household contacts.

Additional file 2: Table S1. Knowledge and attitudes among index patients.

\section{Abbreviations}

OR: Odds ratio; TB: Tuberculosis; RCT: Randomised controlled trial; WHO: World Health Organization.

\section{Competing interests}

The authors declare that they have no competing interests.

\section{Authors' contributions}

GJF, LPL and GBM conceived of the study, and participated in its design and coordination and helped to draft the manuscript. NVN DNS and WJB participated in its design and coordination and contributed to the manuscript. NTL participated in its coordination and implementation and contributed to the manuscript. All authors read and approved the final manuscript.

\section{Acknowledgements}

The study was funded by the Australian National Health and Medical Research Council (APP ID 632781). GJF was supported by NHMRC Postgraduate Award (APP ID 571220) and CJ Martin Early Career Fellowship (APP ID 1054107). Dr Paul Mason and Dr Thu Anh of the Woolcock Institute of Medical Research contributed to reviewing the manuscript.

\section{Author details}

'Woolcock Institute of Medical Research, University of Sydney, 431 Glebe Point Road, Glebe, Sydney 2037, Australia. ${ }^{2}$ Sydney Medical School, University of Sydney, Sydney 2006, Australia. ${ }^{3}$ National Lung Hospital, 463 Hoang Hoa Tham Street, Ba Dinh, Hanoi, Vietnam. ${ }^{4}$ Centenary Institute of Cancer Medicine and Cell Biology, University of Sydney, Missenden Road Camperdown, Sydney 2050, Australia. ${ }^{5}$ South Western Sydney Clinical School, University of New South Wales, Sydney 2052, Australia.

Received: 26 September 2014 Accepted: 10 February 2015

Published online: 26 February 2015

\section{References}

1. World Health Organization. Global tuberculosis report 2014. In: Book Global tuberculosis report 2014. City: Geneva: WHO; 2014.

2. Kasaie P, Andrews JR, Kelton WD, Dowdy DW. Timing of tuberculosis transmission and the impact of household contact tracing: an agent-based simulation model. Am J Respir Crit Care Med. 2014;189(7):845-52.

3. Murray CJ, Salomon JA. Modeling the impact of global tuberculosis control strategies. Proc Natl Acad Sci U S A. 1998;95:13881-6.

4. Fox GJ, Barry SE, Britton WJ, Marks GB. Contact investigation for tuberculosis: a systematic review and meta-analysis. Eur Respir J. 2013;41:134-50.

5. Ayles H, Muyoyeta M, Du Toit E, Schaap A, Floyd S, Simwinga M, et al. Effect of household and community interventions on the burden of tuberculosis in southern Africa: the ZAMSTAR community-randomised trial. Lancet. 2013;382(9899):1183-94.

6. Recommendations for the investigation of contacts of persons with infectious tuberculosis in low and middle income countries. [http://www. who.int/tb/publications/2012/contact_investigation2012]

7. World Health Organization Stop TB Partnership Childhood TB Subgroup. Chapter 4: childhood contact screening and management. Int J Tuberc Lung Dis. 2007;11:12-5.

8. World Health Organization. WHO Three I's Meeting. In Book WHO Three I's Meeting. City: Geneva; 2008.

9. Hwang TJ, Ottmani S, Uplekar M. A rapid assessment of prevailing policies on tuberculosis contact investigation. Int J Tuberc Lung Dis. 2011;15:1620-3.

10. Hill PC, Rutherford ME, Audas R, van Crevel R, Graham SM. Closing the policy-practice gap in the management of child contacts of tuberculosis cases in developing countries. PLoS Med. 2011;8:e1001105.

11. Rutherford ME, Ruslami R, Anselmo M, Alisjahbana B, Yulianti N, Sampurno $\mathrm{H}$, et al. Management of children exposed to Mycobacterium tuberculosis: a public health evaluation in West Java, Indonesia. Bull World Health Organ. 2013;91:932-41. A.

12. Tornee S, Kaewkungwal J, Fungladda W, Silachamroon U, Akarasewi P, Sunakorn P. Factors associated with the household contact screening adherence of tuberculosis patients. SE Asian J Trop Med. 2005;36:331-40.

13. Nyirenda M, Sinfield R, Haves S, Molyneux EM, Graham SM. Poor attendance at a child TB contact clinic in Malawi. Int J Tuberc Lung Dis. 2006;10:585-7.

14. Thanh TH, Ngoc SD, Viet NN, Van HN, Horby P, Cobelens FG, et al. A household survey on screening practices of household contacts of smear positive tuberculosis patients in Vietnam. BMC Public Health. 2014;14:713.

15. Fox GJ, Nhung NV, Sy DN, Britton WJ, Marks GB. Household contact investigation for tuberculosis in Vietnam: study protocol for a cluste randomized controlled trial. Trials. 2013;14:342.

16. Fox GJ, Nhung NV, Sy DN, Lien LT, Cuong NK, Britton WJ, et al. Contact investigation in households of patients with tuberculosis in hanoi, Vietnam: a prospective cohort study. PLoS One. 2012;7:e49880

17. Strauss A, Corbin J. Grounded theory methodology, Handbook of qualitative research. 1994. p. 273-85.

18. EpiData Data Entry, Data Management and basic Statistical Analysis System. [Http://www.epidata.dk]

19. PROC MI002E [http://www.sas.com (Accessed at 18 Jun 2014)]

20. Long NH, Johansson E, Diwan VK, Winkvist A. Different tuberculosis in men and women: beliefs from focus groups in Vietnam. Soc Sci Med. 1999:49:815-22

21. Dye C, Glaziou P, Floyd K, Raviglione M. Prospects for tuberculosis elimination. Annu Rev Publ Health. 2013:34:271-86.

22. World Health Organization. Systematic screening for active tuberculosis: principles and recommendations. Geneva: WHO; 2013. WHO/HTM/TB/ 2013.04. Located at: http://www.who.int/tb/tbscreening/en/ [Last accessed $1 / 2 / 2015]$

23. Koch E. Free market tuberculosis. Nashville, USA: Vanderbilt University Press; 2013. 
24. Ayisi JG, van't Hoog AH, Agaya JA, McHembere W, Nyamthimba PO, Muhenje O, et al. Care seeking and attitudes towards treatment compliance by newly enrolled tuberculosis patients in the district treatment programme in rural western Kenya: a qualitative study. BMC Public Health. 2011;11:515.

25. Muture BN, Keraka MN, Kimuu PK, Kabiru EW, Ombeka VO, Oguya F. Factors associated with default from treatment among tuberculosis patients in Nairobi province, Kenya: a case control study. BMC Public Health. 2011;11:696.

26. Shargie EB, Lindtjorn B. Determinants of treatment adherence among smear-positive pulmonary tuberculosis patients in Southern Ethiopia. PLoS Med. 2007;4:e37.

\section{Submit your next manuscript to BioMed Central} and take full advantage of:

- Convenient online submission

- Thorough peer review

- No space constraints or color figure charges

- Immediate publication on acceptance

- Inclusion in PubMed, CAS, Scopus and Google Scholar

- Research which is freely available for redistribution 